\title{
Roughness influence on the sheet resistance of the PEDOT:PSS printed on paper
}

\author{
Rogério M. Morais, Maykel S. Klem, Maíza S. Ozório*, Tiago C. Gomes, Neri Alves \\ São Paulo State University (UNESP), School of Technology and Applied Sciences, Campus Presidente Prudente, SP, Brazil
}

\section{A R T I C L E I N F O}

\section{Article history:}

Received 7 August 2017

Received in revised form

8 November 2017

Accepted 13 November 2017

Available online 14 November 2017

Keywords:

Electronics paper

PEDOT:PSS

Resistivity

Roughness

Inkjet printing

\begin{abstract}
A B S T R A C T
The use of paper as a platform to manufacture organic electronic devices, electronic paper, has expanding potential for many applications because of several properties offered. In this work, we show a study of PEDOT:PSS printed by inkjet on bond paper, vegetal paper and sheets of PET. The relation between the surface density of the deposited material, morphology and resistivity was investigated for samples printed with a commercial Hewlett-Packard(HP) ${ }^{\circledR}$ printer and Microsoft Word ${ }^{\circledR}$ software. The amount of material deposited, i.e. surface density, was controlled using the print number in the same position and changing the gray scale used in the image formation. Changing the surface density of printed PEDOT:PSS it is possible to produce a continuous film permeating the papers fibers. Sheet resistances obtained, when $7.0 \mathrm{mg} \mathrm{cm}^{-2}$ of PEDOT:PSS were deposited on the surfaces, were: (a) $413.2 \mathrm{k} \Omega / \mathrm{Sq}$ for bond paper, (b) $5.6 \mathrm{k} \Omega / \mathrm{Sq}$ for vegetable paper and (c) $2.3 \mathrm{k} \Omega / \mathrm{Sq}$ for PET. The exponential dependence of sheet resistance with the surface density of printed material allows us to evaluate the strong influence of substrate roughness on PEDOT:PSS conductivity and to predict, for each one, conditions to minimize it.
\end{abstract}

() 2017 Elsevier B.V. All rights reserved.

\section{Introduction}

Interest in printed organic electronics is expanding because it enables production of devices such as solar cells, photovoltaic panels and displays covering large areas, as well as applications in chemical and biological sensors. Among printing methods, the inkjet printing technique stands out, allowing well defined patterning without using a lithographic process and providing a reduction in cost and waste, as well as advantages in prototyping developments and production of custom circuits. Paper is a material that has increasingly gained the attention of the scientific community looking for new substrates for organic electronic devices, since several studies have pointed to its use as a substrate [1-6]. In this context we address the production of printed organic electronics by the printing of poly(3,4ethylenedioxythiophene):poly(styrenesulfonate) (PEDOT:PSS), one of the most frequently used polymers for electrodes or active layers, onto paper.

Paper is constituted of cellulose fiber, obtained mostly from tree trunks, wattled with hydrogen bonds. Its use in everyday life has

\footnotetext{
* Corresponding author.

E-mail address: ozoriounesp@gmail.com (M.S. Ozório).
}

become almost inevitable and, for a long time, paper has been one of the most used materials in the world. Only recently has it been used in scientific and technological applications, for exemple as a substrate in the preparation of electronic devices [7-9]. The use of paper as a platform to manufacture organic electronics devices is known as electronics paper [10,11] and its attraction is due to several properties offered, one of which is that it is one of the most abundant and cheapest materials in the world, lightweight, disposable, foldable, flexible, recyclable and biodegradable, besides, chemically and thermally stable. Moreover, depending on the desired application, characteristics considered problematic, such as porosity and roughness may become advantageous. For instance, in sensors which are important the interaction of the analyte with the sensing material, the paper rougheness increase the contact area. Also, supercapacitor and lab-on-a-chip (LOC) are another examples where the porosity and roughness are advantageous, promoting diffusion and capillarity. An application that illustrates the potential of paper in circuit printing is the application in smart packaging [6]. We have already used paper, in previous work, as a substrate to print polyaniline [12] and copper tetrasulfonated phthalocyanine [13] aiming to explore its potential for printing circuits, by ink jet printer, and its applications as sensors.

PEDOT:PSS is a conjugated polymer (a mixture of two ionomers) widely used in printed organic electronics due to its high electrical 


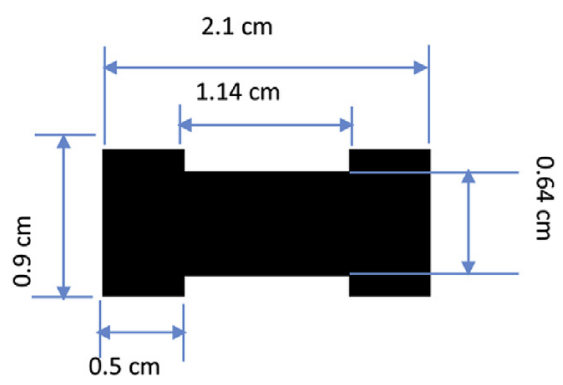

Fig. 1. Schematic representation of the design and dimensions printed on paper.

Table 1

Relation between tonality and surface density for $\mathrm{N}_{\mathrm{p}}=1$.

\begin{tabular}{|c|c|c|}
\hline Tonality & RGB components & $\begin{array}{l}\text { Medium surface density of mass } \\
\text { per printing } \\
\mathrm{D}_{\mathrm{s}}\left(\mathrm{mg} \mathrm{cm}^{-2}\right)\end{array}$ \\
\hline $\mathrm{T}_{1}$ & (192 192 192) & $0.09 \pm 0.05$ \\
\hline $\mathrm{T}_{2}$ & (144 144 144) & $0.12 \pm 0.02$ \\
\hline $\mathrm{T}_{3}$ & (969696) & $0.17 \pm 0.04$ \\
\hline $\mathrm{T}_{4}$ & (48 4848$)$ & $0.36 \pm 0.03$ \\
\hline $\mathrm{T}_{5}$ & $\left(\begin{array}{lll}0 & 0 & 0\end{array}\right)$ & $0.70 \pm 0.03$ \\
\hline
\end{tabular}

conductivity [14], high transparency, low redox potential, good processability, high thermal stability and light resistance $[15,16]$. Its first commercial application was in an antistatic layer [15] and, later, gained market in several other applications, for example, solid electrolyte capacitors, printed circuit boards, packaging films, touch screens, hole transport layers in organic light emitting diodes (OLEDs) [17], organic photovoltaic devices (OPV) [18-20] and transparent electrodes [21,22].

The deposition of PEDOT:PSS on paper substrate, aimed at producing electronic circuits is actually a very interesting theme $[23,24]$. Although it was reported that paper coated with PEDOT: PSS can present sheet resistance as low as $5.5 \Omega \Omega^{-1}[25]$ this value is still bigger than other substrates or self-supporting films. Dennelin et al. found that pristine PEDOT:PSS resistivity is 100 times greater than on a substrate of paper or plastic [24]. Kawashima [26] polymerized PEDOT directly on the paper obtaining resistivity of $0.6 \Omega \mathrm{cm}$. They show that the conductive polymer form thin membranes attached to the surface of the cellulose fibers with thick leaves extended through empty space between them. The conductivity of PEDOT: PSS printed on paper depends heavily on roughness and surface tension. Studies show that the roughness of the paper strongly influences its conductivity even when metallic inks [27] or metals by evaporation $[10,28]$ are deposited. Despite this variability and roughness influence, it is possible to observe standard behaviors without any treatment of the paper surface. This is important because, when the purpose is to produce organic electronic devices in paper substrate, by an easy route, surface treatment has to be avoided.

In this work we show a study of PEDOT:PSS printed by inkjet on two paper types, bond paper (BP) and vegetal paper (VP), and sheets of polyethylene terephthalate (PET). The relation between the amount of PEDOT:PSS deposited with the substrate roughness and resistivity, was investigated for samples printed using a commercial printer. It was shown that it is possible to produce a continuous film permeating the paper fibers, and that, by controlling the amount of material deposited on the paper, it is possible to obtain a good resistivity tuning.

\section{Materials and methods}

A Hewlett-Packard ${ }^{\circledR}$ (HP) commercial desk jet printer, model J110a, series 1000, was used to print PEDOT:PSS on BP, VP and PET, in order to obtain different surface roughness. A solution in the proportion of $2: 1: 1(\mathrm{v}: \mathrm{v}: \mathrm{v})$ was prepared adding conductive grade PEDOT:PSS, purchased from Sigma-Aldrich ${ }^{\circledR}$ - product code: 483095 , to ethylene glycol diluted in ultrapure water (Milli-Q) and was left stirring for about two hours and was then filtered using Millex ${ }^{\circledR}$ HV PVDF $0.45 \mu \mathrm{m}$ filters. The original cartridge was opened, the ink, sponge and internal filter were removed and, in order to eliminate all residues, a careful cleansing was performed using 2propanol alcohol $\left(\left(\mathrm{CH}_{3}\right)_{2} \mathrm{CHOH}\right)$ and deionized water.

Patterns were designed using the Microsoft Word ${ }^{\circledR}$ software and printed with the dimensions shown in Fig. 1. To control the material quantity deposited on the substrate, several printings were performed in the same positions associated with the tonality. The number of printing is referred to in this text as printing number $\left(\mathrm{N}_{\mathrm{P}}\right)$ and five levels of tonality named $\mathrm{T}_{1}, \mathrm{~T}_{2}, \mathrm{~T}_{3}, \mathrm{~T}_{4}$ and $\mathrm{T}_{5}$ were chosen. In practice these levels were obtained by modifying the composition of colors shown on the display, selecting the customized color patterns option and inputting the desired RGB components, and finally printing it, with a resolution of $600 \times 600$ dot pixels per inch (DPI), using only the black cartridge (monochrome), for the printing with different gray scales. The RGB components (192 192 192), (144144 144), (96 96 96), (48 48 48) and $\left(\begin{array}{lll}0 & 0 & 0\end{array}\right)$ were used to obtain $\mathrm{T}_{1}, \mathrm{~T}_{2}, \mathrm{~T}_{3}, \mathrm{~T}_{4}$ and $\mathrm{T}_{5}$, respectively.

In this work $\mathrm{N}_{\mathrm{P}}$ was changed from 1 to 12 for different tonalities and, as soon as they were printed, the samples were left in a desiccator with silica gel for at least $24 \mathrm{~h}$ before starting the measurements. The printing was performed on BP and VP with a grammage of $75 \mathrm{~g} \mathrm{~m}^{-2}$ and $92 \mathrm{~g} \mathrm{~m}^{-2}$, respectively, and on PET. The substrate of PET was treated with plasma for $5 \mathrm{~min}$ while the substrates of paper did not receive any treatment.
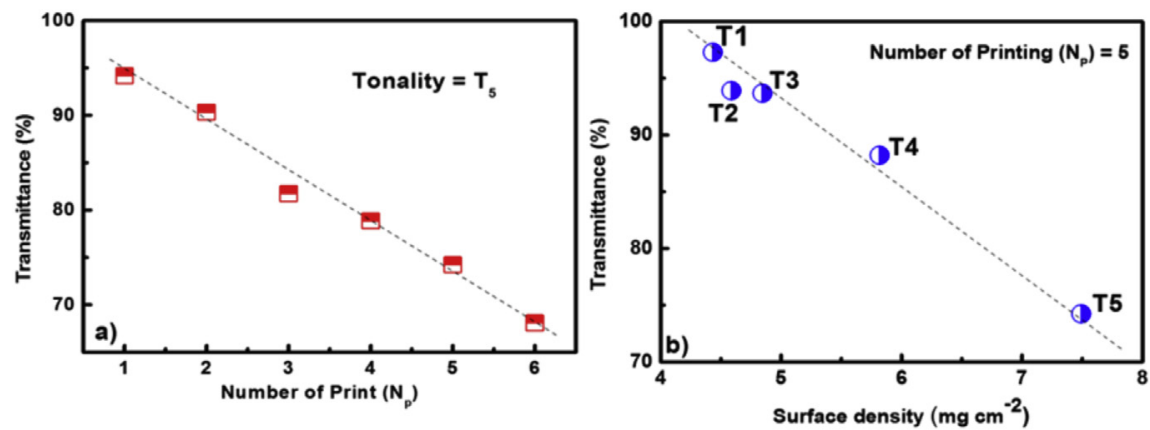

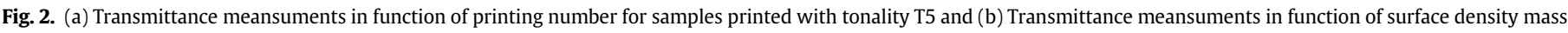
changing the tonality from $\mathrm{T} 1$ to $\mathrm{T} 5$. 

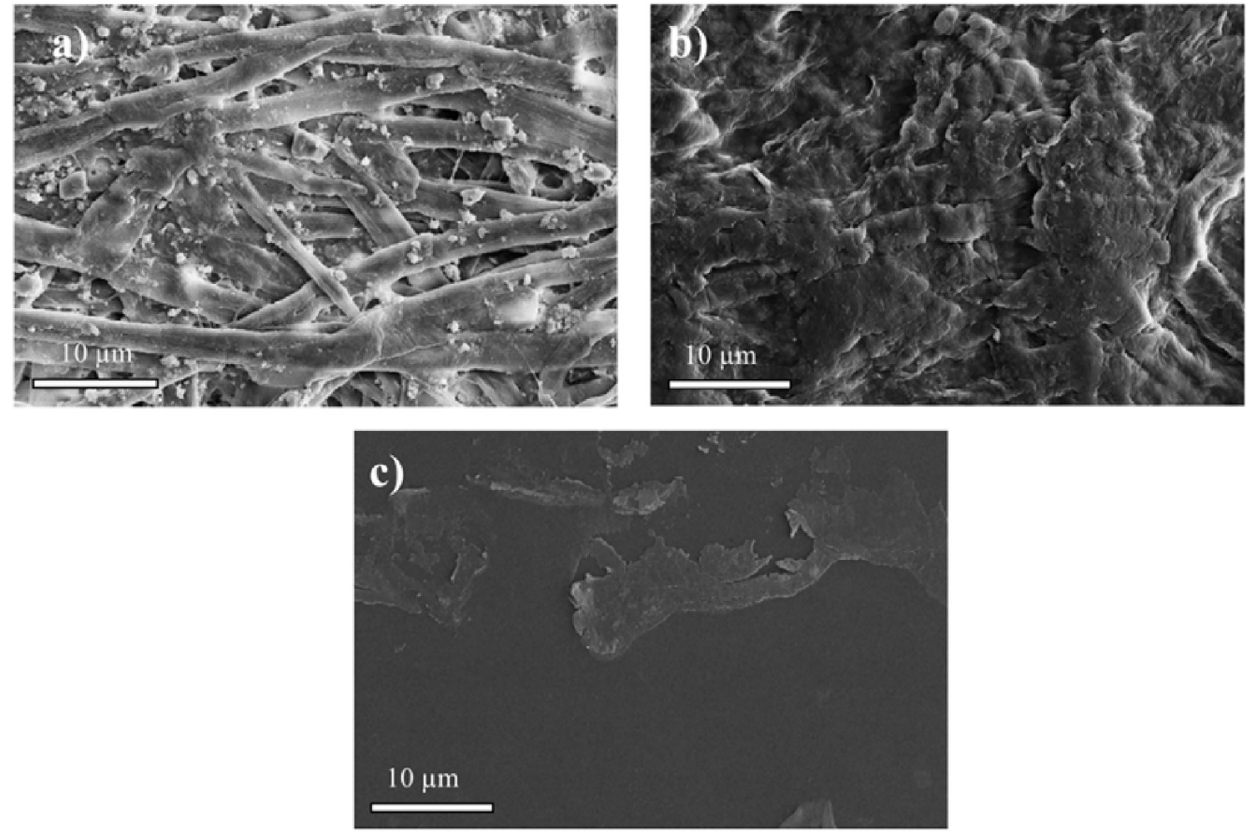

Fig. 3. SEM image of (a) BP, (b) VP and (c) PET. Scale bar: $10 \mu \mathrm{m}$. Magnification: $10.000 \times$.

The sheet resistance measurement, using the four probes method, were performed in air. The current and the voltage is controlled by a Keitlhey 2420 source and a Keitlhey 617 electrometer. For investigations of morphological aspects, images were obtained with Carl Zeiss Scanning Electrical Microscopy (SEM), model EVO LS 15 operating in secondary electrons mode (ES) and dispersive electrons mode (EDS) and a Nanosurf Atomic Force Microscope (AFM), model Easy Scan 2. An analytical balance,
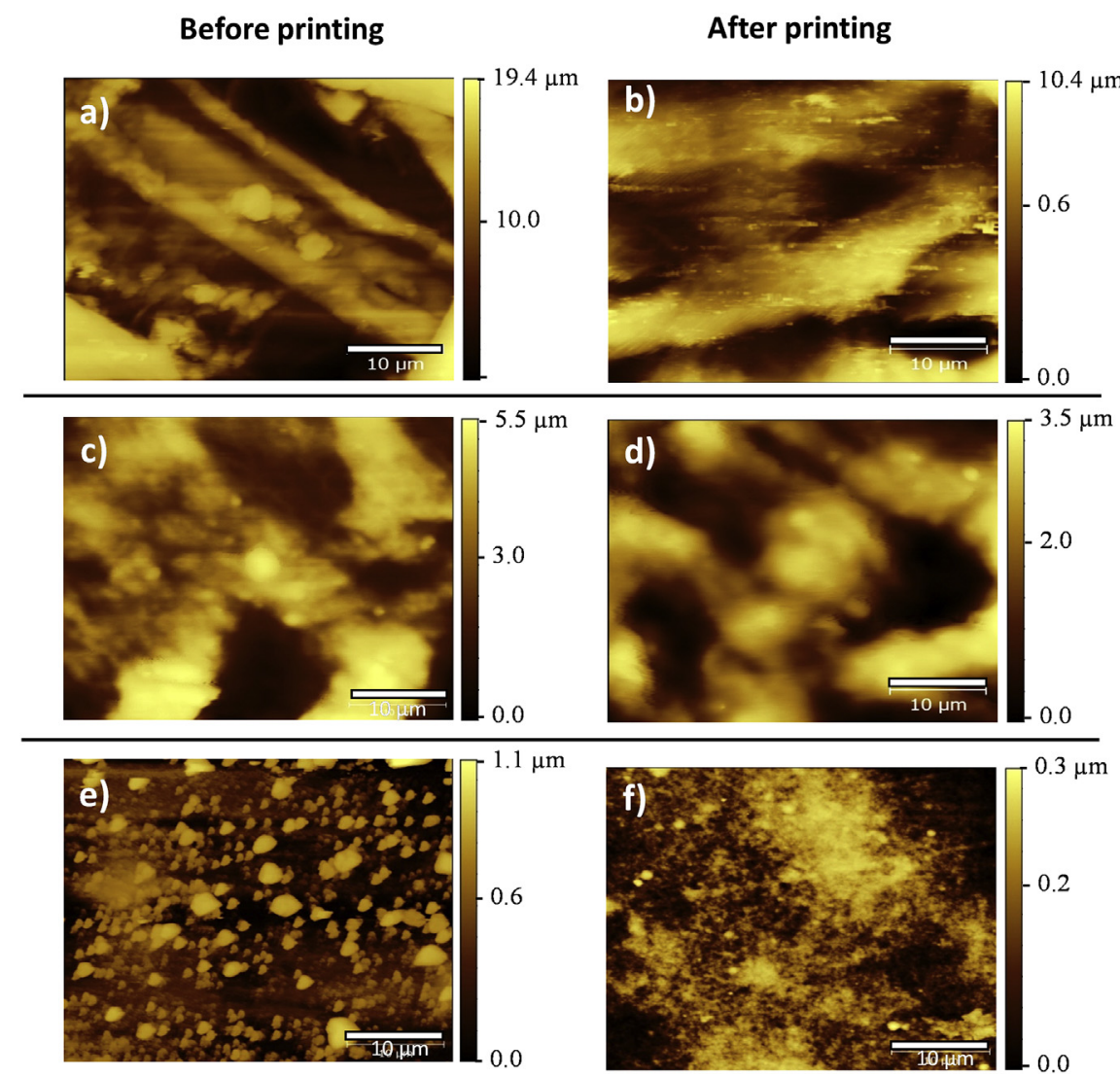

Fig. 4. AFM image (a), (c) and (e) for pristine BP, VP and PET respectively. AFM images (b), (d) and (f) for BP, VP and PET after printing PEDOT:PSS respectively. The scanned area is $40 \mu \mathrm{m} \times 40 \mu \mathrm{m}$ 
Table 2

Values of roughness of substrates after and before five printings with tonality $\mathrm{T}_{5}$

\begin{tabular}{llll}
\hline Substrate & $\mathrm{R}_{\mathrm{A}}(\mathrm{nm})$ & $\mathrm{R}_{\mathrm{B}}(\mathrm{nm})$ & $\mathrm{R}_{\mathrm{A}} / \mathrm{R}_{\mathrm{B}}$ \\
\hline Bond Paper (BP) & 1750 & 55.4 & 31.6 \\
Vegetal Paper (VP) & 540 & 153.1 & 3.5 \\
PET & 730 & 32.7 & 2.2 \\
\hline
\end{tabular}

Shimadzu model AUW220D was used to quantify the amount of material deposited and an FTIR spectrophotometer, Bruker model Tensor 27, was used for transmittance measurements.

\section{Results and discussion}

Initially, the relation between the tonality and surface density of PEDOT:PSS mass deposited was investigated. For this, first of all, five printings $\left(\mathrm{N}_{\mathrm{P}}=5\right)$ of PEDOT:PSS were performed in $10 \mathrm{~cm}^{2}$ of VP with each tonality; was then the transmittance in each one measured. The surface density of mass $\left(\mathrm{mg} \mathrm{cm}^{-2}\right)$ was determined by weighing the printed paper on an analytical balance and comparing it with pristine VP. The RGB components used for each tonality and the correspondent medium surface density of mass for one printing is shown in Table 1. Before to perform the weighing of the printed paper, as well as transmittance measurements, the samples were dried by keep them in a desiccator with silica gel during $24 \mathrm{~h}$. These measurements were performed in room temperature $\left(25^{\circ} \mathrm{C}\right)$ and humidity of $40 \%$, immediately after take out the samples from the desiccator.

The plot of transmittance versus printing number for tonality $\mathrm{T}_{5}$ is shown in Fig. 2a. Transmittance versus surface density of mass is shown in Fig. 2b. In the latter figure the tonality is changing from T1 to $\mathrm{T} 5$, as indicated in the plot and $\mathrm{Np}$ is kept constant $\left(\mathrm{N}_{\mathrm{P}}=5\right)$. A linear relation is observed in both plots. The abscissa axis of Fig. 2 refers to the total surface density of mass obtained multiplying the correspondent value of each tonality by the printing number.

The transmittance decreases and the surface density of mass increases when the tonality changes from $T_{1}$ to $T_{5}$. In fact, this is expected since the transmittance depends on the amount of material deposited on the paper. Thus, the results shown in Fig. $2 \mathrm{a}$ and $b$, i.e. the linear dependence of transmittance, $T$, with $N_{P}$ and with the surface density of mass, confirms that is possible to control the amount of PEDOT:PSS printed on the paper changing these parameters. It is worth emphasizing that the tonality, $\mathrm{T}$, and the printing number, Np, are the two parameters that enable control of the surface density of the printed material and that they can be used complementarily.

The electrical characteristics of the samples coated with PEDOT: PSS depend fundamentally on their morphology. The SEM images of substrates are shown in Fig. $3 a-c$ where it can be observe that the surfaces of the papers are more irregular and rough than the PET surface. It can also be seen that the surface of VP is more uniform than that of BP.

Fig. 4 shows AFM images of printing PEDOT:PSS in a scanned area of $40 \mu \mathrm{m} \times 40 \mu \mathrm{m}$ being that Fig. $4 \mathrm{a}$, c and e were obtained before and, Fig. 4b, d and $\mathrm{f}$ after printing in BP, VP and PET, respectively. The values obtained for the roughness before printing $\left(R_{A}\right)$, and after $\left(R_{B}\right)$, and the ratio between them $\left(R_{A} / R_{B}\right)$ are shown for each substrate in Table 2. After printing PEDOT:PSS with a surface density of the $3.5 \mathrm{mg} \mathrm{cm}^{-2}$ ( 5 printings with $\mathrm{T}_{5}$ ), roughness was reduced by about 2.2 for PET, 3.5 for VP and 31.6 times for BP, evidencing that successive printings can produce a coating with a lower surface roughness than the surface or the substrate (see Fig. 4b, d and f).

The images, obtained by EDS, for sulfur (S) in BP with two, three and four printings, using tonality $\mathrm{T}_{5}$, are shown in Fig. 5a, b and c, respectively. Sulfur was chosen because it integrates the molecular structure of PEDOT:PSS and is not found in the composition of paper. The sulfur in PEDOT:PSS is indicated in the red regions of the images. We can see that, after only two printings, $\left(1.4 \mathrm{mg} \mathrm{cm}^{-2}\right)$ the concentration is very low, resulting in sparse spots, while, for three printings, there is a quantity sufficient to form a continuous film wrapping the fibers, but, with some defects. A film starts to form when the spots overlap each other, creating a continuous path that is referred to in this text as percolated deposition. When the printing number is four $\left(2.8 \mathrm{mg} \mathrm{cm}^{-2}\right)$, the intensity of the EDS signal for sulfur is intense, compared with the lower printing number, and characterizes a bigger concentration of PEDOT:PSS. An image obtained from the EDS sulfur signal for four printings $\left(2.8 \mathrm{mg} \mathrm{cm}^{-2}\right.$ ) in BP is shown in Fig. $5 \mathrm{~d}$, in lateral view. We can verify a film of PEDOT:PSS with thickness estimated as approximately $20 \mu \mathrm{m}$ that partly permeates the paper fibers. After reaching the percolation condition, each new printing will contribute to reducing the surface defects and increasing the PEDOT:PSS film thickness. The thickness of the film deposited can be estimated by the relation $t=D s / D v$, where Ds is the surface density of PEDOT:PSS mass deposited on paper and Dv the volumetric density. Using this relation, a thickness of $28 \mu \mathrm{m}$ is obtained for these conditions (4 printings with $\mathrm{T}_{5}$ ). The difference can be explained by the fact that, in the first printings, the ink is absorbed by the paper, sinking into the depth of the fibers.

The sheet resistance of the substrates coated with PEDOT:PSS was related to surface density. The plot of sheet resistance versus 1/ $D_{S}$ in di-log scale is shown in Fig. 6a, and for better visualization there is an auxiliary axis on top of the plot with Ds in a linear scale. The plot in function of $1 / D_{s}$ was chosen because, in the case of printed material forming a homogeneous and continuous film over the substrate, a linear decreasing of sheet resistance with the thickness would be expected. In first approximation a strip the PEDOT:PSS printed on paper can be considered as uniform layer with length $(\mathrm{L})$, width $(\mathrm{W})$ and thickness $(\mathrm{t})$ as draw in Fig. $6 \mathrm{~b}$. The electrical resistance trough the strip is given by $\mathrm{R}=\left[\rho . \mathrm{L} .(\mathrm{W} . \mathrm{t})^{-1}\right]$, where $\rho$ is the resistivity and the ratio $\mathrm{Lw}^{-1}$ is the number of square $\left(\mathrm{N}_{\mathrm{S}}\right)$ of the strip. Thus, the sheet resistance (Rs), defined as the resistance divided by $\mathrm{N}_{\mathrm{s}}$, can be written as $\mathrm{R}_{\mathrm{S}}=\left[\rho \cdot \mathrm{t}^{-1}\right]$. Being the volumetric density written as the relation of mass $(\mathrm{m})$ by volume, we have that $\left.D_{V}=[m \text {.(W.L.t })^{-1}\right]$. In same way we can defined a surface density material by the relation of mass by surface area write as $D_{S}=\left[\mathrm{m} .(\mathrm{W} . \mathrm{L})^{-1}\right]$. Thus the thickness $t$ also can expressed by $t=\left[D s . D v^{-1}\right]$. Is worth to emphasize that only for homogeneous and uniform film that Dv is the density volumetric characteristic of the material. From the relation showed above the sheet resistance of a strip can be written as $R s=\left[D_{\mathrm{v}} \cdot\left(\rho \cdot D_{s}\right)^{-1}\right]$. That is, it is expected that the sheet resistance will be proportional to the of surface density of mass. But, this linear relation is not observed experimentally. Instead, the sheet resistance exhibits an exponential dependence with $\mathrm{Ds}^{-1}$ that can be empirically expressed as

$R_{S}=C\left(\frac{1}{D_{S}}\right)^{n}$

In accordance with Fig. 6, the value of $n$ depends on the substrate and on the range used for the surface density of mass (Ds). In $\mathrm{BP}$, when the surface density of mass is bigger than $2.1 \mathrm{mg} \mathrm{cm}^{-2}$, all the points fit in a straight line with a slope $n_{1}=3.3$. This mean that for the surface density of printed material bigger than $2.1 \mathrm{mg} \mathrm{cm}^{-2}$ there is a percolation of areas covered with PEDOT:PSS, as discussed above concerning the SEM image (see Fig. 5b).

Considering the aligned points, in experimental curves, as indicating that the substrate was covered and a continuous and 

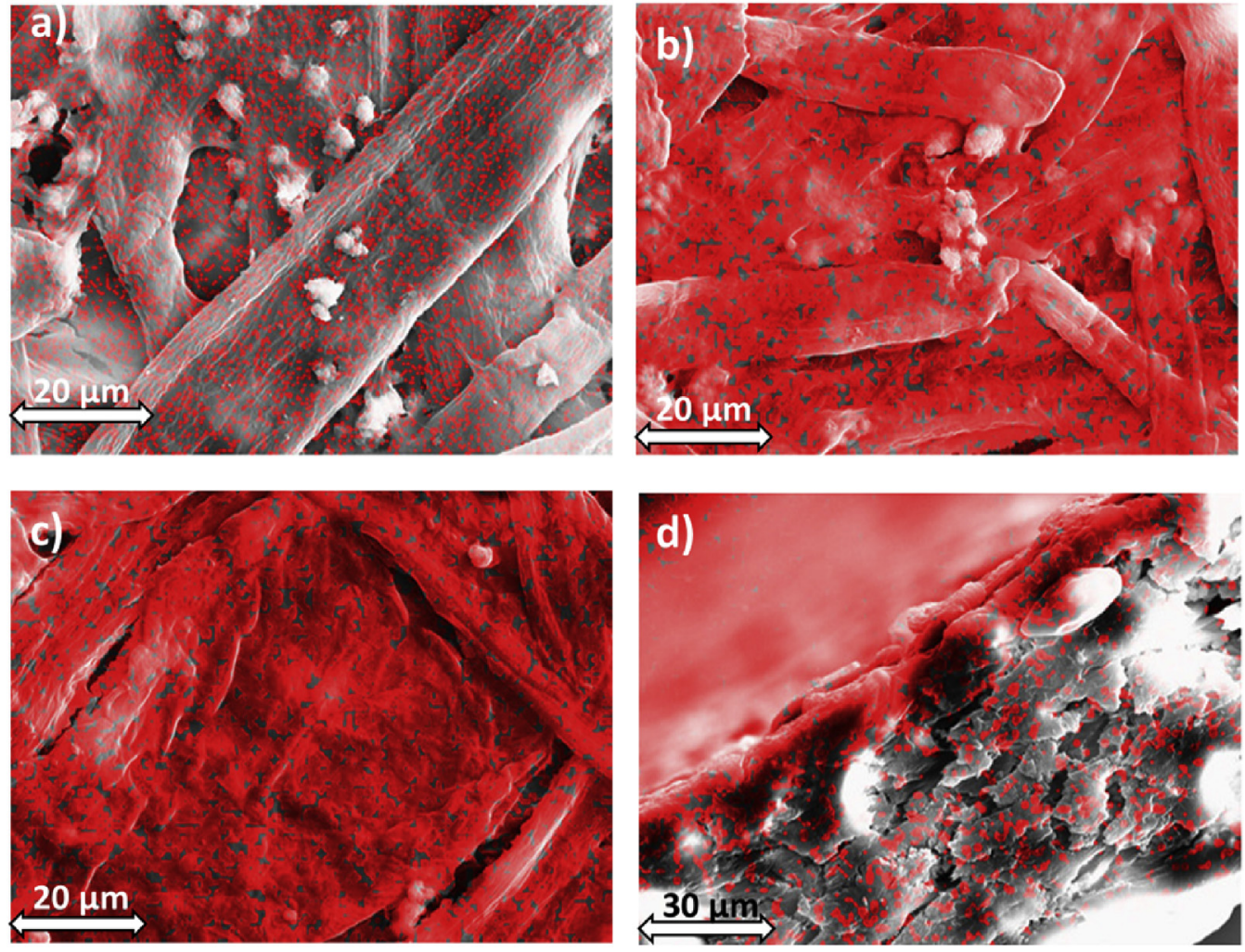

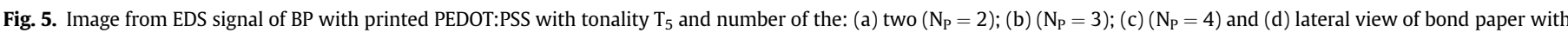
four printings $\left(\mathrm{N}_{\mathrm{P}}=4\right)$.
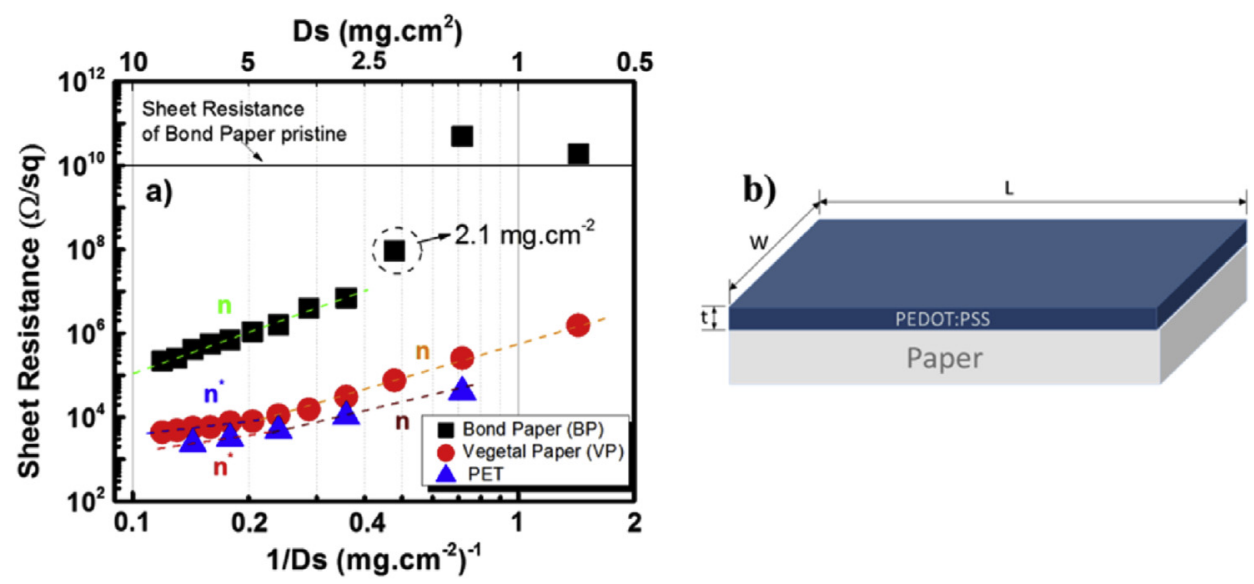

Fig. 6. (a) Sheet resistance in function of inverse of the surface density. (b) Illustration of the a strip the PEDOT:PSS printed on paper.

homogeneous film was formed, this film formation is also observed in VP and PET. In VP, a formation of the film occurs from the first printing with $\mathrm{T}_{5}$ that corresponds to $0.7 \mathrm{mg} \mathrm{cm}^{-2}$ (three times smaller than in BP). Furthermore, in the VP, it is possible to observe two regimes with different slopes $\left(\mathrm{n}=2.8\right.$ and $\left.n^{*}=1.5\right)$. The same behavior is observed in films printed onto PET, though, with lower slopes $\left(n=2\right.$ and $\left.n^{*}=1.4\right)$. The values of $n$ and of the surface roughness of each substrate is shown in Table 3. The slope obtained with the linear fit for the first set of aligned points, observed for small printing numbers, is simply named $n$, while the slope for the second segment is named $n^{*}$. For BP the points start to be aligned after four printings, however VP and PET they are aligned from the first early printings. We consider that the influence of the substrate
Table 3

Values of $n^{*}$ and $n$ and for each substrates roughness. Here there is not any value for $n^{*}$ relative to BP, because due to its high roughness there is not any change in the slope, same with very high surface density of PEDOT:PSS.

\begin{tabular}{llll}
\hline Substrate & Roughness $(\mu \mathrm{m})$ & $\mathrm{n}$ & $\mathrm{n}^{*}$ \\
\hline Bond Paper & 1.75 & 3.3 & \\
Vegetal & 0.54 & 2.8 & 1.5 \\
PET & 0.073 & 2.0 & 1.4 \\
\hline
\end{tabular}

roughness is stronger for the firsts printing. In this way, the exponent $n$ refers to the situation in which the influence of substrate roughness is stronger and $n^{*}$ refers to a situation in which it is 
lower. The exponent $n^{*}$ is not observed for BP because even with a large amount of printed PEDPOT:PSS, the substrate is still influencing a lot of the value of the surface resistivity. The roughness in BP is 3.2 times greater than in VP. Because of this, even a surface density of mass as high as $8.5 \mathrm{mg} \mathrm{cm}{ }^{-2}$ is not enough to reach $n^{*}$, which characterizes a regime in which the roughness no longer has any influence on the sheet resistance (in BP curves there is only one slope). With VP, after printing PEDOT:PSS with a density of $5.0 \mathrm{mg} \mathrm{cm} \mathrm{cm}^{-2}$ there is an inflection point, changing the slope to $n^{*}=1.5$. We can say that the exponent $n$ is approximating to the unit, that is, it is going in the direction of the ohmic regime. In the films formed on PET, we can see the same behavior from a surface density of $4.0 \mathrm{mg} \mathrm{cm}^{-2}$, when we will have $n^{*}=1,4$. Summarizing, for rougher substrates, such as BP, a large amount of print ink material is necessary to minimize the irregularity of the surface, and to reach the percolation and form a film over the surface. For less rough substrates, such as PET, it is possible to minimize the surface irregularities and to form films with a lower amount of print ink material.

As discussed before, the $n$ value is obtained when the influence of the substrate is great. The plot of $n$ versus the roughness for each substrate utilized is shown in Fig. 7. An exponential relationship can be seen between the $n$ values and the roughness (linear in log scale). The extrapolation of the graph shows that $n \cong 1$ for roughness (rms) in the order of $1 \mathrm{~nm}$. Although there are only three differents substrates, this analyses give us a first approximation of the great influence of substrate roughness in the PEDOT:PSS film resistivity. Also, taking data as reference we can infer that to obtain an ohmic regime, the substrates will be needed with a roughness in order of $1 \mathrm{~nm}$.

In order to produce film on BP, the printing should be at least $2.8 \mathrm{mg} \mathrm{cm}^{-2}$ when, according to SEM pictures taken of the lateral view, shown in Fig. 5d, has a continuous film with approximately $28 \mu \mathrm{m}$ permeating the fibers on the top of the paper. Considering this condition, and using the relation $\mathrm{R}_{\mathrm{S}}=\left[\rho \cdot \mathrm{t}^{-1}\right]$, it can be calculated, from Fig. 6, that the resistivity of film printed on BP is $19,7 \mathrm{k} \Omega \mathrm{cm}$, while, in the manufactures guide, the value $1.0 \Omega \mathrm{cm}$ is cited as reference [29]. It can be speculated that this large increase in sheet resistance of PEDOT:PSS printed on paper could be attributed to dedopping produced by the paper's chemistry [27]. An investigation was therefore carried out with Raman spectroscopy (not shown), however, the Raman spectrums were absolutely identical, showing no trace of a dedopping process. So it can be confirmed that the great variability of the resistivity is due only to the effect of roughness. In fact, it is known that paper roughness produces an increase in the resistivity even in the metallic conductor material deposited on it $[10,28,30]$. Siegel et al. [28],

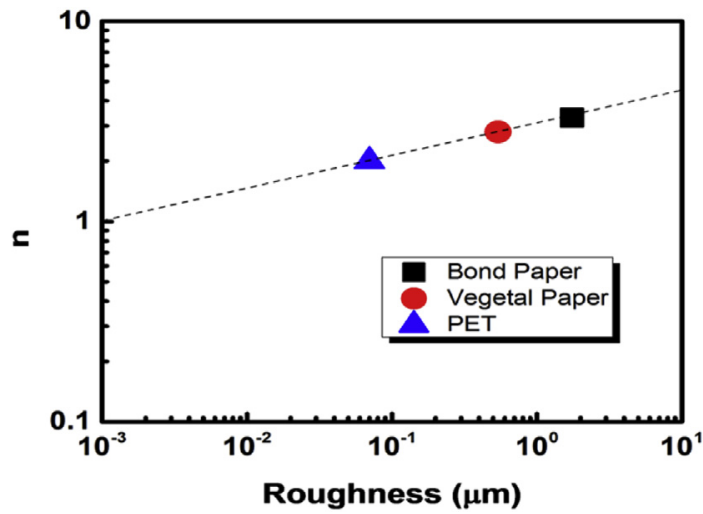

Fig. 7. Plot of exponent $n$ in function of roughness of the substrate. show that the conductivity of metals deposited on BP is reduced four times due to the influence of roughness. The increase of the PEDOT:PSS resistivity on BP was also observed in results presented by Denneulin [24] showing, when PEDOT:PSS high conductivity is deposited on paper, its conductivity is reduced approximately 100 times. These studies seem to indicate that the substrate roughness has the effect of increasing the resistivity of printed layers on its and it is also dependent on its resistivity.

\section{Conclusions}

To summarize, in our work we have demonstrated that: i) with a commercial thermal printer, associating gray scale (tonality) with the printing number, it is possible to control the surface density of mass deposited; ii) depending on the density and roughness of the substrate, the morphology of the printed PEDOT:PSS can be in the form of sparse spots, a percolated coverage where the spots are overlapping each other creating a continuous path of PEDOT, or a continuous film on the surface; iii) the roughness of the surface of the PEDOT:PSS film becomes lower as the printing number increases; iv) the sheet resistance decreases exponentially when the surface density of PEDOT:PSS increases, where the value of exponent $n$, obtained with low surface density, is related with the substrate roughness; v) when the surface density of PEDOT:PSS increases, the exponent $\mathrm{n}$ decreases, approximating to 1 . This means that, after printing a high surface density of mass, the sheet resistance becomes inversely proportional to the total amount of material printed. The roughness effect of the substrate can only be ignored with roughness as low as $1 \mathrm{~nm}$ rms. It is believed that the results presented here are important to the design of different applications in electronic paper.

\section{Acknowledgements}

The authors thank the Coordenação de Aperfeiçoamento de Pessoal de Nível Superior (CAPES) and Programa de Pós-Graduação em Ciência dos Materiais (POSMat) for their financial support.

\section{References}

[1] J. Rolland, D. Mourey, Paper as a novel material platform for devices, MRS Bull. 38 (2013) 299-305.

[2] J.E. Mates, I.S. Bayer, M. Salerno, P.J. Carroll, Z. Jiang, L. Liu, C.M. Megaridis, Durable and flexible graphene composites based on artists' paint for conductive paper applications, Carbon N. Y. 87 (2015) 163-174.

[3] Y. Feng, L. Xie, Q. Chen, L.-R. Zheng, Low-cost printed chipless RFID humidity sensor tag for intelligent packaging, IEEE Sens. J. 15 (2015) 3201-3208.

[4] D. Tobjörk, R. Österbacka, Paper electronics, Adv. Mater. 23 (2011) 1935-1961.

[5] G. Zheng, Y. Cui, E. Karabulut, L. Wågberg, H. Zhu, L. Hu, Nanostructured paper for flexible energy and electronic devices, MRS Bull. 38 (2013) 320-325.

[6] L. Xie, Y. Feng, M. Mantysalo, Q. Chen, L.R. Zheng, Integration of f-MWCNT sensor and printed circuits on paper substrate, IEEE Sens. J. 13 (2013) 3948-3956.

[7] J.P. Rolland, D.A. Mourey, Paper as a novel material platform for devices, MRS Bull. 38 (2013) 299-305.

[8] L. Huang, P. Jiang, D. Wang, Y. Luo, M. Li, H. Lee, R.A. Gerhardt, A novel paperbased flexible ammonia gas sensor via silver and SWNT-PABS inkjet printing, Sens. Actuators B Chem. 197 (2014) 308-313.

[9] N. Liu, K.N. Yun, H.-Y. Yu, J.H. Shim, C.J. Lee, High-performance carbon nanotube thin-film transistors on flexible paper substrates, Appl. Phys. Lett. 106 (2015) 103106.

[10] D. Tobjörk, R. Österbacka, Paper electronics, Adv. Mater. 23 (2011) 1935-1961.

[11] B. Trnovec, M. Stanel, U. Hahn, A.C. Hübler, H. Kempa, R. Sangl, M. Forster, Coated Paper for Printed Electronics, 2009, pp. 48-51.

[12] T.C. Gomes, C.J.L. Constantino, E.M. Lopes, A.E. Job, N. Alves, Thermal inkjet printing of polyaniline on paper, Thin Solid Films 520 (2012) 7200-7204.

[13] T.C. Gomes, R.F. de Oliveira, É.M. Lopes, M. dos Santos Klem, D.L. da Silva Agostini, C.J.L. Constantino, N. Alves, Effects of humidity on the electrical properties of thermal inkjet-printed films of copper tetrasulfonated phthalocyanine (CuTsPc) onto paper substrates, J. Mater. Sci. 50 (2014) 2122-2129. 
[14] A.M. Nardes, M. Kemerink, M.M. de Kok, E. Vinken, K. Maturova, R.A.J. Janssen, Conductivity, work function, and environmental stability of PEDOT: PSS thin films treated with sorbitol, Org. Electron. Phys. Mater. Appl. 9 (2008) $727-734$.

[15] L. Groenendaal, F. Jonas, D. Freitag, H. Pielartzik, J.R. Reynolds, Poly(3,4ethylenedioxythiophene) and its derivatives: past, present, and future, Adv. Mater. 12 (2000) 481-494

[16] X. Qian, J. Shen, G. Yu, X. An, Influence of pulp fiber substrate on conductivity of polyaniline-coated conductive paper prepared by in-situ polymerization, BioResources 5 (2010) 899-907.

[17] A. Elschner, F. Bruder, H.-W. Heuer, F. Jonas, A. Karbach, S. Kirchmeyer, S. Thurm, R. Wehrmann, PEDT/PSS for efficient hole-injection in hybrid organic light-emitting diodes, Synth. Met. 111-112 (2000) 139-143.

[18] A. Elschner, S. Kirchmeyer, W. Lovenich, U. Merker, K. Reuter, PEDOT: Principles and Applications of an Intrinsically Conductive Polymer, CRC Press, 2010.

[19] F. Zhang, M. Johansson, M.R. Andersson, J.C. Hummelen, O. Inganäs, Polymer photovoltaic cells with conducting polymer anodes, Adv. Mater. 14 (2002) 662-665.

[20] P. Schilinsky, U. Asawapirom, U. Scherf, M. Biele, C.J. Brabec, Influence of the molecular weight of poly(3-hexylthiophene) on the performance of bulk heterojunction solar cells, Chem. Mater. 17 (2005) 2175-2180.

[21] H. Chang G. Wang A. Yang X. Tao, X. Liu, Y, Shen, Z Zheng A transparent, flexible, low-temperature, and solution-processible graphene composite electrode, Adv. Funct. Mater. 20 (2010) 2893-2902.
[22] D.J.D. Moet, P. de Bruyn, P.W.M. Blom, High work function transparent middle electrode for organic tandem solar cells, Appl. Phys. Lett. 96 (2010) 153504.

[23] S.H. Eom, S. Senthilarasu, P. Uthirakumar, S.C. Yoon, J. Lim, C. Lee, H.S. Lim, J. Lee, S.H. Lee, Polymer solar cells based on inkjet-printed PEDOT: PSS layer Org. Electron. Phys. Mater. Appl. 10 (2009) 536-542.

24] A. Denneulin, A. Blayo, J. Bras, C. Neuman, PEDOT: PSS coating on specialty papers: process optimization and effects of surface properties on electrica performances, Prog. Org. Coat. 63 (2008) 87-91.

25] J. Zhou, T. Fukawa, H. Shirai, M. Kimura, Anisotropic motion of electroactive papers coated with PEDOT/PSS, Macromol. Mater. Eng. 295 (2010) 671-675.

[26] H. Kawashima, M. Shinotsuka, M. Nakano, H. Goto, Fabrication of conductive paper coated with PEDOT: preparation and characterization, J. Coat. Technol. Res. 9 (2012) 467-474.

[27] H. Zhu, Z. Jia, Y. Chen, N. Weadock, J. Wan, O. Vaaland, X. Han, T. Li, L. Hu, Tin anode for sodium-ion batteries using natural wood fiber as a mechanical buffer and electrolyte reservoir, Nano Lett. 13 (2013) 3093-3100.

[28] A.C. Siegel, S.T. Phillips, M.D. Dickey, N. Lu, Z. Suo, G.M. Whitesides, Foldable printed circuit boards on paper substrates, Adv. Funct. Mater. 20 (2010) 28-35.

29] Product Specification, SIGMA-ALDRICH, (n.d.) 63103.

[30] A. Phongphut, C. Sriprachuabwong, A. Wisitsoraat, A. Tuantranont S. Prichanont, P. Sritongkham, A disposable amperometric biosensor based on inkjet-printed Au/PEDOT-PSS nanocomposite for triglyceride determination, Sens. Actuators B Chem. 178 (2013) 501-507. 